\title{
Ultrasound Evaluation of the Uterine Scar Thickness after Single Versus Double Layer Closure of Transverse Lower Segment Cesarean Section
}

\author{
Mohamed Nabih EL-Gharib, Ahmad M Awara \\ Department of Obstetrics and Gynecology, Faculty of Medicine, Tanta University, Tanta, Egypt
}

\section{A B S T R A C T}

Background: The degree of the lower uterine segment (LUS) thinning and the risk of uterine scar defect have been studied. However, the relationship between the methods of closure and the degree of thinning needs further elucidation. Aim: The aim of this study was to determine whether a LUS transverse cesarean section (CS) closure method in one or two layers affects subsequent scar thickness. Subjects and Methods: In this prospective study, 150 women were enrolled and randomly assigned to one- or two-layer closure of the LUS incision. Patients were divided into two groups. Each group included 75 patients, of primigravidae with gestational age from 38 weeks to 40 weeks one group had a single layer closure and the other had a double layer closure. Results: We found an increase in the thickness of LUS-CS scar in cases with double layer closure of the incision than a single layer closure as depicted by ultrasonography after 2 days and 2 weeks post-operative. Conclusion: These findings suggest that the number of closing layers of CS directly affect the thickness of the scar.

KEY WORDS: Cesarean section, one layer, scar thickness, two layers

\section{INTRODUCTION}

Cesarean section (CS) is the delivery of a fetus through an abdominal and uterine incision; technically, it is a laparotomy followed by a hysterotomy ${ }^{[1]}$ The number of deliveries by CS has been increasing steadily world-wide in recent decades. CS is also associated with long-term risks such as adhesions, uterine scar rupture, and placental complications. The latter two complications are likely to be associated with the poor uterine scar healing following CS. ${ }^{[2]}$

Regarding Egypt, a significant rise in cesarean deliveries has occurred for all births from $4.6 \%$ in 1992 to $10.3 \%$ in 2000. However, hospital based cesarean deliveries were much higher in 1988 (13.9\%), increasing to $22.0 \%$ in 2000. Although, the CS rate was slightly higher in private hospitals, the rate also increased consistently in the public hospitals. ${ }^{[3]}$

The uterus may be closed with interrupted or continuous sutures in 1, 2 or 3 layers. Observational studies have suggested that a single-layer closure is associated with

\begin{tabular}{|l|l|}
\hline \multicolumn{2}{|c|}{ Access this article online } \\
\hline Quick Response Code & Website: \\
\hline & www.jbcrs.org \\
\hline & \\
\hline
\end{tabular}

scar defects and is more likely to dehisce in subsequent pregnancies. ${ }^{[4]}$ However, a sensitivity analysis indicated that the risk of uterine rupture was increased after a locked single-layer closure but not after an unlocked single-layer closure, compared with a double-layer closure. ${ }^{[5]}$ Recent findings suggest a strong association between the degree of the lower uterine segment (LUS) thinning and the risk of uterine scar defect. ${ }^{[6]}$

Transvaginal sonography is a new tool to assess uterine scar thickness in women with a previous Cesarean delivery to determine the critical thickness above, which safe vaginal delivery. ${ }^{[7]}$

Several investigators have reported a strong association between the degree of LUS thinning and the risk of uterine scar defect, ${ }^{[6]}$ therefore, thickness of CS scar may serve as an excellent predictor of uterine scar defect in women contemplating vaginal birth after cesarean section. An ideal cut-off value cannot be recommended, underlining the need for more standardized measurement techniques. ${ }^{[7,8]}$

The aim of this study is to evaluate the uterine scar thickness by ultrasonography in women randomly assigned to one or two layer closure of the uterine incision after primary

Address for correspondence
Prof. Mohamed Nabih EL-Gharib,
Department of Obstetrics and Gynecology, Faculty of Medicine,
Tanta University, Tanta, Egypt.
E-mail: mohgharib@hotmail.com


cesarean delivery and in addition to prove or disprove the relative beneficial effect of each for myometrium closure.

\section{SUBJECTS AND METHODS}

Patients were recruited from both the out-patient clinic and the inpatient wards of Obstetrics and Gynecology Department in Tanta University Hospital, Tanta, Egypt during the period from July 2010 to June 2012.

Patients were approached for participation if their delivery was a scheduled primary elective cesarean delivery due to fetal or maternal causes.

This study was carried out on 150 patients, divided into two groups (A and B). Each group included 75 primigravidae with gestational age from 38 weeks to 40 weeks. Group-A: Underwent single layer closure of transverse lower segment CS. A one-layer closure usually involves a single continuous, locking layer of absorbable suture (0 Vicryl sutures). Group-B: Underwent double layer closure of transverse lower segment CS. A two-layer closure typically adds an imbricating layer of absorbable suture (0 Vicryl sutures). The research was approved by the Ethical Committee of Tanta Faculty of Medicine.

All the participants' names were hidden and replaced by code numbers to maintain the privacy. After obtaining written consent and confirming entry into the study, each patient was assigned a treatment group by selection of the next consecutive envelope. The group-Allocation was revealed to the surgeon during the surgery just before the repair.

Exclusion criteria were multiple gestations, abnormalities of fetal heart rate, polyhydramnios, uterine malformation, anterior placenta previa, placenta accreta, uterine or cervical fibroid, fetal macrosomia, any previous uterine operation or any medical disease that compromises wound healing as diabetes mellitus, collagen diseases or anemia.

Patients had an ultrasonographic evaluation of the LUS immediately preoperative (baseline) and then follow-up measurements at $48 \mathrm{~h}, 2$ weeks, and 6 weeks postoperatively. All sonographic measurements were carried out in the Department of Obstetrics and by one staff member who was duly trained for the purpose.

Baseline measurements were obtained by measuring the myometrial thickness in the mid-sagittal plane by transabdominal ultrasonography at a point below the reflection of the bladder in a technique described by Buhimschi et al ${ }^{[9]}$ The device used was (LOGIQ ${ }^{\mathrm{TM}} 100$ PRO), serial no.: 60725WS9, manufactured by: Wipro GE Health Care Private Ltd.
Postoperative evaluation of the uterine incision involved identifying the uterine scar as described by Koutsougeras et al..$^{[10}$ and measuring the scar in the mid-sagittal plane perpendicular to the uterine wall by transabdominal or transvaginal approach, governed by the station of the presenting part and placental localization. All ultrasonographic examinations were performed with an ultrasound machine LOGIQ $^{\mathrm{TM}} 100$ PRO.

\section{RESULTS}

The general characteristics of the population for each study period are reported in Table 1. The differences between the two groups for maternal age, gestational age at delivery, mean thickness of the LUS before the operation, neonatal birth weight and the duration of postoperative hospital stay statistically insignificant.

The most common indications for CS delivery are depicted in Table 2. The commonest indications were: Malpresentations, extreme degree of contracted pelvis, oligohydraminos, and placental abruption with unfavorable cervix, posterior placenta previa, and meconium with unfavorable cervix.

The mean (SD) duration of operation in group-A was 43.7 (7.1) min while in group-B it was 47.7 (5.9) min. The difference between both groups is significant $(P=0.03)$.

As regards anesthetic complications, succinyl choline apnea occurred in 1 case of group-A. Atonic post-partum

\begin{tabular}{lccc}
\hline \multicolumn{4}{c}{ Table 1: General characteristics of the study groups } \\
\hline Item & $\begin{array}{c}\text { Group A } \\
\text { (single-layer) }\end{array}$ & $\begin{array}{c}\text { Group B } \\
\text { (double-layer) }\end{array}$ & $P$ \\
\hline Mother age in years & $28.84(3.4)$ & $28.36(3.2)$ & 0.60 \\
Gestational age in weeks & $39.11(0.7)$ & $39.16(0.7)$ & 0.70 \\
Duration of the operation in minutes & $43.86(7.1)$ & $47.68(5.9)$ & 0.035 \\
Hospital stay in days & $1.48(0.8)$ & $1.6(0.9)$ & 0.53 \\
Birth weight in kg & $2.86(0.6)$ & $2.87(0.6)$ & 0.84 \\
Thickness of LUS before the operation & $4.80(0.8)$ & $5(1.0)$ & 0.40 \\
in mm & & & \\
\hline LUS - Lower uterine segment & & &
\end{tabular}

\begin{tabular}{l|c|c|c|c}
\hline \multicolumn{5}{c}{ Table 2: The indications of CS in the cases } \\
\hline Indications of CS operation & Group A N=75 & Group B N=75 \\
\cline { 2 - 5 } & $\mathrm{n}$ & $\%$ & $\mathrm{n}$ & $\%$ \\
\hline Fetal & 12 & 16 & 9 & 12 \\
$\quad$ Oligohydramnios & 24 & 32 & 30 & 40 \\
Mal-presentations & 6 & 8 & 3 & 4 \\
Meconium with unfavorable cervix & 6 & 8 & 6 & 8 \\
Mild placental abruption with unfavorable & & & & \\
cervix & 3 & 4 & 3 & 4 \\
$\quad$ Genital herpes & & & & \\
Maternal & 12 & 16 & 9 & 12 \\
$\quad$ Extreme degree of contracted pelvis & 6 & 8 & 6 & 8 \\
Posterior placenta previa & 2 & 2.67 & 3 & 4 \\
$\quad$ Condyloma acuminata & 3 & 4 & 3 & 4 \\
$\quad$ Displaced pelvic fracture & 1 & 1.33 & 3 & 4 \\
$\quad$ Successful repair of vesico-vaginal fistula & 75 & 100 & 75 & 100 \\
\hline Total & & & & \\
\hline CS - Caesarean section &
\end{tabular}


hemorrhage occurred in two cases of group-A. Wound sepsis occurred in 9 cases ( 3 from group-A and 6 from group-B).

In this study, transvaginal ultrasound was carried out for five cases of group-A while 70 cases of this group underwent trans-abdominal ultrasonography. However, in group-B seven cases underwent transvaginal ultrasound, while the remaining 68 cases underwent trans-abdominal ultrasonography.

LUS thickness evaluated by ultrasound 2 days after CS for cases of group-A ranged from $20 \mathrm{~mm}$ to $30 \mathrm{~mm}$ with a mean (SD) of 25.5 (3.5) $\mathrm{mm}$. In group- $\mathrm{B}$, the analogs values ranged from $25 \mathrm{~mm}$ to $36 \mathrm{~mm}$ with a mean of $28.5(3.6) \mathrm{mm}$. The difference between both groups is significant $(P<0.01)$.

LUS thickness 2 weeks after CS judged by ultrasonography revealed that its' value for cases of group-A ranged from $14 \mathrm{~mm}$ to $20 \mathrm{~mm}$ with a mean (SD) $16.8(2.2) \mathrm{mm}$. The corresponding values in group-B ranged from $16 \mathrm{~mm}$ to $25 \mathrm{~mm}$ with a mean of $19.4(2.7) \mathrm{mm}$. The difference between both groups is significant $(P<0.01)$.

\section{DISCUSSION}

CS is one of the most commonly performed major abdominal operations in women in both affuent and low-income countries. Rates vary considerably between countries and health services. ${ }^{[11-13]}$

For emergency surgery, $55 \%$ of obstetricians use single-layer closure of the uterine incision, $37 \%$ use double-layer closure while $11 \%$ use single-layer closure only in women undergoing concomitant sterilization. ${ }^{[14]}$

Closure of the hysterotomy site has gained interest because of the potential relationship with uterine rupture during a trial of labor in the future pregnancies..$^{[15-17]}$

Several techniques for myometrium closure have been described, including the use of interrupted, locked, and unlocked continuous sutures with single-or double-layer closure. ${ }^{[18]}$

Uterine closure may be performed with either a single-or double-layer closure technique. Single-layer closure using a running locking stitch has been shown to be associated with decreased operative time and fewer additional hemostatic sutures. A large Canadian study found a four-fold increase in the risk of uterine rupture in a woman who had a single layer closure in their previous pregnancy. ${ }^{[19-23]}$

In the existing investigation, we found that the duration of one layer technique operation for closure of uterine incision was significantly shorter than that for two-layer technique.
This matches with Ferrari and associates who instituted that one layer technique has a shorter operating times. ${ }^{[24]}$

The ultrasonographic measurement of the thickness of the LUS is useful for deciding the best type of delivery for patients. The knowledge of this ultrasound measurement may explain the differences in the results for both study groups: Among patients with one previous CS, concern about a thin lower segment probably contributed to increase the rate of elective CS while knowledge of a thick myometrium helped to reduce the rate of CS during labor, by lowering the fear of uterine rupture. ${ }^{\mid 25]}$

From the contemporary study, it is evident that the LUS scar measured $48 \mathrm{~h}$ post-operatively was significantly thicker among women submitted to two-layer technique of hysterotomy closure than those submitted to a single-layer closure technique $(P=0.003)$.

Furthermore, we displayed that the mean LUS-CS scar thickness 2 weeks post-operative was significantly thicker among women submitted to two-layer technique of hysterotomy closure than those submitted to a single layer closure technique $(P=0.0005)$.

Hamar et al. disclosed insignificant variations in the lower segment hysterotomy scar thickness at $48 \mathrm{~h}$ and 2 weeks postoperatively between one-layer compared with two-layer closure technique of the hysterotomy incision. They concluded that uterine scar thickness diminishes progressively after both one- or two-layer closure, but does not vary with the mode of hysterotomy closure. ${ }^{[26]}$

\section{REFERENCES}

1. Gabert HA, Bey M. History and development of cesarean operation. Obstet Gynecol Clin North Am 1988;15:591-605.

2. Ofili-Yebovi D, Ben-Nagi J, Sawyer E, Yazbek J, Lee C, Gonzalez J, et al. Deficient lower-segment Cesarean section scars: Prevalence and risk factors. Ultrasound Obstet Gynecol 2008;31:72-7.

3. Khawaja M, Jurdi R, Kabakian-Khasholian T. Rising trends in cesarean section rates in Egypt. Birth 2004;31:12-6.

4. Hofmeyr JG, Novikova N, Mathai M, Shah A. Techniques for cesarean section. Am J Obstet Gynecol 2009;201:431-44.

5. Roberge S, Chaillet N, Boutin A, Moore L, Jastrow N, Brassard N, et al. Single-versus double-layer closure of the hysterotomy incision during cesarean delivery and risk of uterine rupture. Int J Gynaecol Obstet 2011;115:5-10.

6. Jastrow N, Antonelli E, Robyr R, Irion O, Boulvain M. Inter-observer and intraobserver variability in ultrasound measurement of lower uterine segment after a previous caesarean section. Ultrasound Obstet Gyn 2010;22:130-5.

7. Suzuki S, Sawa R, Yoneyama Y, Asakura H, Araki T. Preoperative diagnosis of dehiscence of the lower uterine segment in patients with a single previous Caesarean section. Aust N Z J Obstet Gynaecol 2000;40:402-4.

8. Gotoh H, Masuzaki H, Yoshida A, Yoshimura S, Miyamura T, Ishimaru T. Predicting incomplete uterine rupture with vaginal sonography during the late second trimester in women with prior cesarean. Obstet Gynecol 2000;95:596-600. 
9. Buhimschi CS, Buhimschi IA, Malinow AM, Weiner CP. Myometrial thickness during human labor and immediately post partum. Am J Obstet Gynecol 2003;188:553-9.

10. Koutsougeras G, Karamanidis D, Chimonis G, Gottas N, Polydorou A, Elmazis $\mathrm{Ch}$, et al. Evaluation during early puerperium of the low transverse incision after cesarean section through vaginal ultrasonography. Clin Exp Obstet Gynecol 2003;30:245-7.

11. Dumont A, de Bernis L, Bouvier-Colle MH, Bréart G, MOMA study group. Caesarean section rate for maternal indication in sub-Saharan Africa: A systematic review. Lancet 2001;358:1328-33.

12. Murray SF, Pradenas FS. Health sector reform and rise of caesarean birth in Chile. Lancet 1997;349:64.

13. Pai M, Sundaram P, Radhakrishnan KK, Thomas K, Muliyil JP. A high rate of caesarean sections in an affluent section of Chennai: Is it cause for concern? Natl Med J India 1999;12:156-8.

14. Dandolu V, Raj J, Harmanli O, Lorico A, Chatwani AJ. Resident education regarding technical aspects of cesarean section. J Reprod Med 2006;51:49-54.

15. Guise JM, Hashima J, Osterweil P. Evidence-based vaginal birth after Caesarean section. Best Pract Res Clin Obstet Gynaecol 2005; 19:117-30.

16. Guise JM, Denman MA, Emeis C, Marshall N, Walker M, Fu R, et al. Vaginal birth after cesarean: New insights on maternal and neonatal outcomes. Obstet Gynecol 2010;115:1267-78.

17. Bujold E, Gauthier RJ. Neonatal morbidity associated with uterine rupture: What are the risk factors? Am J Obstet Gynecol 2002;186:311-4.

18. Berghella V, Baxter JK, Chauhan SP. Evidence-based surgery for cesarean delivery. Am J Obstet Gynecol 2005;193:1607-17.
19. Hauth JC, Owen J, Davis RO. Transverse uterine incision closure: One versus two layers. Am J Obstet Gynecol 1992;167:1108-11.

20. Tucker JM, Hauth JC, Hodgkins P, Owen J, Winkler CL. Trial of labor after a one- or two-layer closure of a low transverse uterine incision. Am J Obstet Gynecol 1993;168:545-6.

21. Chapman SJ, Owen J, Hauth JC. One- versus two-layer closure of a low transverse cesarean: The next pregnancy. Obstet Gynecol 1997;89:16-8.

22. Bujold E, Bujold C, Hamilton EF, Harel F, Gauthier RJ. The impact of a single-layer or double-layer closure on uterine rupture. Am J Obstet Gynecol 2002;186:1326-30.

23. Stone IK. Suture materials. Clin Obstet Gynecol 1988;31:712-7.

24. Ferrari AG, Frigerio LG, Candotti G, Buscaglia M, Petrone M, Taglioretti A, et al. Can Joel-Cohen incision and single layer reconstruction reduce cesarean section morbidity? Int J Gynaecol Obstet 2001;72:135-43.

25. Rozenberg P, Goffinet F, Philippe HJ, Nisand I. Thickness of the lower uterine segment: Its influence in the management of patients with previous cesarean sections. Eur J Obstet Gynecol Reprod Biol 1999;87:39-45.

26. Hamar BD, Saber SB, Cackovic M, Magloire LK, Pettker CM, Abdel-Razeq SS, et al. Ultrasound evaluation of the uterine scar after cesarean delivery: A randomized controlled trial of one- and two-layer closure. Obstet Gynecol 2007;110:808-13.

How to cite this article: EL-Gharib MN, Awara AM. Ultrasound evaluation of the uterine scar thickness after single versus double layer closure of transverse lower segment cesarean section. J Basic Clin Reprod Sci 2013;2:42-5. Source of Support: Nil, Conflict of Interest: None declared

\section{"Quick Response Code" link for full text articles}

The journal issue has a unique new feature for reaching to the journal's website without typing a single letter. Each article on its first page has a "Quick Response Code". Using any mobile or other hand-held device with camera and GPRS/other internet source, one can reach to the full text of that particular article on the journal's website. Start a QR-code reading software (see list of free applications from http://tinyurl.com/ yzlh2tc) and point the camera to the QR-code printed in the journal. It will automatically take you to the HTML full text of that article. One can also use a desktop or laptop with web camera for similar functionality. See http://tinyurl.com/2bw7fn3 or http://tinyurl.com/3ysr3me for the free applications. 